\title{
Third-party Provision of Conversion Technologies in Network Markets
}

\author{
Arnaud X. Varé 1,*, Ralf W. Seifert ${ }^{1,2}$
}

\begin{abstract}
In network markets, the provision of third-party converters is an important dimension of standards wars. In this paper, we develop a mathematical model to analyze the effects of third-party converter introduction on the adoption process of incumbents' base technologies and discuss managerial insights based on our model. We determine converter introduction strategies of third parties by establishing under what circumstances third parties may maximize their profit. We find that there exists an optimal introduction time for converters, which depends on a trade-off between conversion option and consumers' memory effect. The preferred conversion option is mostly two-way conversion. As a result of converter provision, converter introduction affects the de facto standardization process of the incumbents' base technologies by accelerating the lock-in process of the dominant technology. We then discuss how incumbents can anticipate and react to third-party converter introduction in order to reduce the third parties' incentive to introduce converters. Throughout the paper, we illustrate our analytical results with numerical examples.
\end{abstract}

Keywords: converter; de facto standardization process; network externality; standards war; tactics; technology adoption; third party.

\footnotetext{
' Ecole Polytechnique Fédérale de Lausanne (EPFL). College of Management of Technology (CDM). Chair of Technology \& Operations Management (TOM). CH - I0I5 Lausanne, Switzerland. arnaud.vare@a3.epfl.ch (corresponding author)

2 IMD - International Institute of Management Development. Chemin de Bellerive 23 . CH - I00I Lausanne, Switzerland. seifert@imd.ch

* Arnaud X. Varé gratefully acknowledges the financial support of the Swiss National Science Foundation (grant PBELI-I I 0255), which allowed him to pursue part of the presented research at Stanford University, Stanford, CA.
} 


\section{Introduction}

In markets with network externalities - network markets - a persistent challenge is the management of competing technology standards to win battles for technological dominance. While the most prominent example of a standards war has probably been in the video recorder market between VHS and Betamax, there has also been a format war in almost each storage medium: floppy disks, mini-disks, memory cards, DVDs and more recently high-definition DVDs.

In this context, scholars have identified that one way to interconnect incompatible technology networks is the provision of conversion technologies (e.g., Gabel, 1987; Shapiro and Varian, 1999b; David and Bunn, 1988). For example, Microsoft agreed with its rival Novell on developing technologies that allow users to run both the Windows and Linux operating systems on the same computer (Ryst, 2006). Furthermore, technology digitalization nowadays simplifies and speeds up the development of conversion technologies. That is, new standards wars are more likely to end up with conversion being offered rather than being fought out until "the end."

In light of the implications of converter provision on de facto standardization processes, incumbents' concerns to allow for potential converter introduction are legitimate. However, some "market spoilsports" - say third parties - may also play a major role in standards battles by providing converters to the market. For example, in instant messaging technologies, there have been attempts to bridge the major instant messengers networks - like AOL, MSN, Yahoo or ICQ - with programs called Trillian (see Viard and Fan's, 2005 case study) and more recently Universal Messenger Plus. Similarly, in the ongoing war in the voice over IP (VoIP) industry, there exists a program called PSGw which allows Skype users to communicate with other VolP networks like Apple iChat or Windows Live Messenger. In the digital audio industry, there exists software, like Blaze Media Pro, to convert Apple's audio protected files to MP3 or WMA so that they can be played on a music player other than iPod. More recently, Apple's encryption technology has been "reverse-engineered" to ensure interoperability between iPod and competitors' devices (Levine, 2006). A company, Doubletwist Ventures, has been founded to license this conversion technology. Finally, in the browsers war between Fire- fox and Internet Explorer, it is possible to read "Internet Explorer only" sites in Firefox using a program called IE Tab.

Hence, while converter introduction may change the rules of standards battles, third-party provision of converters is another dimension that incumbents of such battles have to consider. Given the business at stake, the need of incumbents to anticipate and react to the introduction of third-party converters is self-evident. Yet, this topic has received relatively little attention. In this paper, we focus on incumbents facing third-party converter introduction. We develop mathematical models to capture the time dynamics of technology adoption for base technologies and converters alike. In particular, we address the following research questions:

I. Which strategies follow third parties to introduce converters between incompatible technologies?

2. What are the effects of third-party converters on the adoption process of competing base technologies? What are the implications on incumbents in terms of creating the market and fighting in de facto standardization processes?

3. Under what conditions do incumbents have to anticipate third-party converter introduction and how should they best react to it?

The remainder of the paper is organized as follows. In Section 2, we review the relevant literature. In Section 3 , we describe our mathematical models for the adoption of base technologies and third-party converters. In Section 4, we analyze implications of third-party converter introduction into the market and discuss managerial insights based on our models. We investigate converter introduction strategies of third parties by determining under what circumstances they can maximize their profit. We find that there exists an optimal introduction time for converters, which depends on a trade-off between conversion option and consumers' memory effect. Third parties favor two-way conversion as conversion option and situations in which both base technologies enter the market at the same time. From the incumbents' perspective, converter introduction affects the de facto standardization process by accelerating the lock-in process of the dominant technology. Not only does this introduction have negative effects on 
weak incumbents (loss of time to re-position), it also impacts dominant incumbents (loss of time to upgrade or develop new products resulting in sales loss). We then discuss which tactics can be used by the incumbents to anticipate or react to converter introduction, in order to reduce the third parties' incentive to introduce converters. In Section 5, we summarize key findings and provide direction for future research.

\section{Literature Review}

We analyze the effects of third-party converters introduced in network markets. We build on the literature on competing standards in the presence of network externalities, which has been extensively reviewed by Farrell and Saloner (1987), David and Greenstein (1990), Swann (2000) and Blind (2004), among others.

An increasing stream of this literature is dedicated to technology conversion and has pointed out the importance of conversion from a strategic perspective. Developing converters between incompatible technologies has indeed been considered as a means to achieve compatibility in fighting standards battles (Braunstein and White, 1985; David and Bunn, 1988; Katz and Shapiro, 1994; Shapiro and Varian, 1999b). In this context, Farrell and Saloner (1992) analyze the implications of converters when there is a conflict between compatibility and variety. Converters may increase compatibility and social welfare only if there is no tendency for the competing technologies to standardize before converters become available. In addition, Choi (1996; 1997) studies the transition from an old technology to an incompatible new technology. He shows that converters can block the transition process to a new technology and thus create market inefficiencies, but improve consumer welfare. Likewise, Andreozzi (2004) demonstrates that converters do not facilitate the transition to a superior technology. Yet, a company could be attracted to develop converters, since they can reduce the critical mass of its own technology while increasing the critical mass of the competitors' technology.

Conversion has also been strategically analyzed from the perspective of providers in terms of conversion alternatives and timing of converter introduction. Manenti and Somma (2008) examine several conversion scenarios to analyze the incentives that firms face in their compatibility decisions. They find that incumbents choose to prevent entrants' technologies from being compatible, while entrants prefer to build a converter to benefit from incumbents' installed bases. Completing the set of scenarios with partial compatibility and considering dynamics of converter introduction, Seifert and Varé (2009) more recently explore effects of incumbent-provided converters. They show that the introduction of such converters may accelerate, extend or reverse the technology lock-in process. They determine that the optimal strategy for weak incumbents is to introduce converters early on, while two-way converters introduced at a later time are optimal for dominant incumbents.

Besides provision by incumbents, converter provision by third parties has been identified as an existing characteristic of standards wars (David, 1987; David and Greenstein, 1990). In this regard, David and Bunn (1988) show that the cost of providing third-party converters may be influenced by the variety of technical systems that need to be made interoperable. From the incumbents' perspective, Economides (1988) models how incumbents can vary their proprietary designs to affect converter costs faced by third parties. Likewise, Farrell and Saloner (1992) suggest that dominant incumbents want converters to be costly to the users. However, while this research discusses potential suppliers' tactics for varying converter costs, it does not examine implications of third-party converter introduction as such on the adoption process of incumbents' base technologies.

We consider third-party converters as complementary products. The literature on complementarities addresses the issue of complementary (or indirect) network externalities. Consumers choose between incompatible technology networks on the basis of the software expected to be available, and the benefits for a hardware good arise as a function of the variety of complementary products (Chou and Shy, 1990; Church and Gandal, 1993; 1996). In particular, Economides and Viard (2007) evaluate the influence of network effects on a base good due to a complementary good. They find that monopolists on base, but not complementary goods, have an incentive to set prices low on base goods to attract customers who use complementary products, even if they are provided by competitors. In spite of that, this literature does not consider that complementary products may have effects on several technology networks, like converters - which correspond to specific complementary products that may have partially compatible interfaces. A recent exception is due to MacKie-Mason and Netz (2006) who allow for one-way

ISSN: 07 I8-2724. (http://www.jotmi.org)

Journal of Technology Management \& Innovation (C) Universidad Alberto Hurtado, Facultad de Economía y Negocios 
converters (called "one-way standards") as an anticompetitive manipulation of interfaces between technologies such that they do not interoperate at the component level. This analysis is restricted to one-way conversion - effects due to two-way conversion are not considered.

In summary, we contribute to the existing literature by investigating converter provision by third parties and consumer adoption of third-party converters. Based on third parties' decisions on converter introduction time and conversion option, we analyze the impact that such complementary products may have on the adoption process of competing base technologies and on incumbents' business.

\section{Mathematical Models}

To address our research questions, we model the adoption of two competing and incompatible base technologies $A$ and $B$ as well as a complementary technology, a third-party converter $C$. We consider an adoption process in three phases, as illustrated in Figure I. In the first phase, time $t \in[0, T)$, converters are not yet available. In the second phase, time $t \in\left[T, t_{\text {lock }}(T)\right)$, converters become available. In the third phase, $t \geq t_{\text {lock }}(T)$, one of the base technologies has locked in the market and is considered as de facto standard in the market.

We distinguish three specific elements of converter sales, depending on the time within the technology adoption process at which they are captured: converter introduction sales, post-introduction sales and lock-in sales.

\subsection{Initial standards war $\quad 3.2$ Adoption of converters and base technologies}

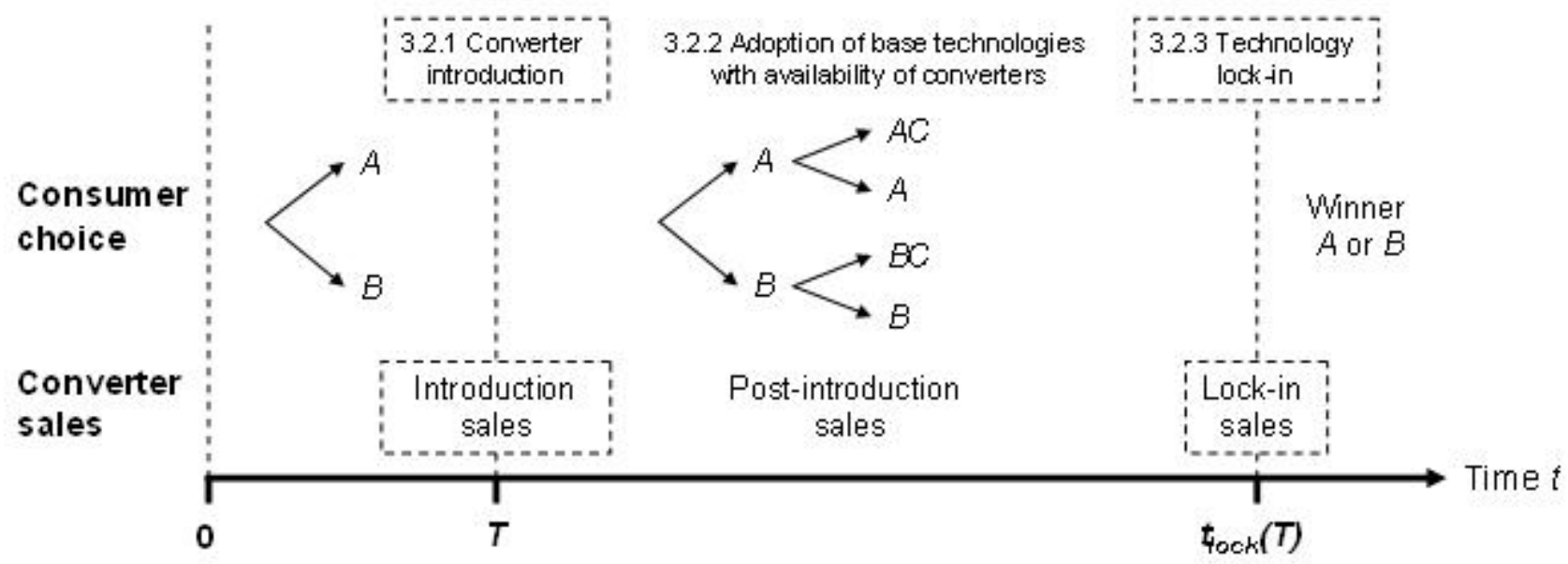

Figure I. Overview of the technology adoption process.

In Subsection 3.I, we present the market dynamics during the initial phase of the technology adoption process, when converters are not yet available. In Subsection 3.2, we focus on the market dynamics from time $T$ onward, once third-party converters have been made available.

\section{I Initial standards war}

The market dynamics during the initial phase of the technology adoption process equate those of a basic standards war between two competing and incompatible technologies. They have been previously analyzed by multiple scholars - we consider Seifert and Varé's (2009) base model of technology adoption and summarize its main constructs here.

Building on Farrell and Saloner's (1986) economic analysis of installed base and compatibility, the adoption of two technologies $A$ and $B$ is modeled. Following Lancaster (1979), technology $i(i \in\{A, B\})$ with product charac- 
teristics $\theta_{i}$ is located on a product space segment $\Theta=$ $[0, I]$. Consumer utilities for technology $i$ are expressed by $u_{i}(t)=\alpha_{i}+\beta_{i} N_{i}(t)$. Here, $\alpha_{i} \geq 0$ represents the standalone value of technology $i$. The strength of the network benefits is captured by $\beta_{i} \geq 0$. The size of network $i$ at time $t$ is denoted by $N_{i}(t)$. Hence, $\beta_{i} N_{i}(t)$ constitutes the network-generated benefits, which correspond to an increase in utility related to network growth over time. As consumers join the market with arrival rate $n(t)=1$, the utilities change over time due to increasing network effects.

Following Hotelling's (1929) linear spatial model, product and customer type spaces are assumed to be identical. Each customer type is presumed to have a most preferred product specification denoted by $X \in \Theta, X$ Uniform $(0, I)$. If $X \neq \theta_{i}$, customers incur a certain disutility $\delta_{i}(X)=\lambda_{i}\left|\theta_{i}-X\right|$, where $\lambda_{i}>0$ represents the customer preference sensitivity.

A consumer adopts the technology for which she has the higher overall utility $\left(u_{i}(t)-\delta_{i}(X)\right)$. The probability function of technology $i, p_{i}(t)$, is therefore defined by:

$$
p_{i}(t)=\frac{\theta_{A} \lambda_{A}+\theta_{B} \lambda_{B}}{\lambda_{A}+\lambda_{B}}+\frac{u_{i}(t)-u_{j}(t)}{\lambda_{A}+\lambda_{B}}
$$

Equation I holds before market lock-in of one competing technology $A$ or $B$ occurs, i.e., for all $t$ such that $p_{i}(t) \in(0 ; I)$.

Given that the number of users at time $t$ is $N_{i}(t)=N_{i}(0)$ $+\int_{0}^{t} n(\tau) p_{i}(\tau) d \tau$, the adoption probability of technology $i$ before lock-in becomes:

$$
p_{i}(t)=\frac{\beta_{j}}{\beta_{A}+\beta_{B}}+\left(p_{i}(0)-\frac{\beta_{j}}{\beta_{A}+\beta_{B}}\right) e^{\frac{\beta_{A}+\beta_{B}}{\lambda_{A}+\lambda_{B}} t}
$$

The adoption probability of technology $j$ is $p_{j}(t)=1-$ $p_{i}(t)$.

\subsection{Adoption of converters and base technolo- gies}

In this subsection, we model the market dynamics from time $T$ onward, when third-party converters $C$ become available (see Figure I). To establish the different converter sales and the adoption of base technologies from time $T$, we model conditional adoption probabilities of third-party converters.

Each consumer joining the market adopts a base technology $A$ or $B$ at time $t_{i} \geq 0(i \in\{A, B\})$. Once converters become available at time $T \geq 0$, all current and new users make a second decision on whether to adopt a converter $C$ at time $t_{c} \geq T$ (where $t_{c} \geq t_{i}$ ). Consumers never buy only $C$. Converters are provided exclusively by third parties, i.e., the providers of technologies $A$ and $B$ do not introduce their own converters.

Consumers adopt a converter $C$ only if their utility from buying a converter are strictly greater than the disutility associated with third-party converters.

The utility from buying a converter, $U_{i}\left(t_{c}\right)$, is composed of normalized utility benefits from conversion $\hat{u}_{i}\left(t_{c}\right)$ and a network effect factor $M\left(t_{c}\right)$, such that $U_{i}\left(t_{c}\right)=$ $\hat{u}_{i}\left(t_{c}\right) M\left(t_{c}\right)$ as follows:

The normalized utility benefits $\hat{u}_{i}\left(t_{c}\right)$ represent consumer utility for technology $i$ as a function of time. Once thirdparty converters have been introduced to the market, the utility of consumers that choose to not purchase such a converter equates $u_{i \bar{C}}(t)=\alpha_{i}+\beta_{i} N_{i}(t)+$ $\mu_{j i} \beta_{j} N_{j c}(t)$. In addition to the stand-alone value $\alpha_{i}$ and the network-generated benefits $\beta_{i} N_{i}(t)$, this utility now includes conversion-generated benefits for technology iusers, $\mu_{j i} \beta_{j} N_{j c}(t)$, where $\mu_{j i} \in[0, I)$ reflect the degrees of conversion. These benefits result from "receiving compatibility benefits" from technology j-users who bought a converter, $N_{j c}(t)$. By buying a converter, consumers of technology $i$ receive compatibility from all users $N_{j}(t)$ of the competing network. That is, consumer utilities for technology $i$ and converter can be expressed as $u_{i, c o n v}(t)$ $=\alpha_{i}+\beta_{i} N_{i}(t)+\mu_{j i} \beta_{j} N_{j}(t)$, with $\mu_{j i} \beta_{j} N_{j}(t)$ being the full conversion-generated benefits. Therefore, the benefits for a technology $i$-user of owning a converter, normalized for comparison purposes over the total conversiongenerated benefits in the market at time $t_{c}$ can be expressed

as

$$
\hat{u}_{i}\left(t_{C}\right)=\frac{u_{i, \text { conv }}\left(t_{C}\right)-u_{i \bar{C}}(t)}{\mu_{i j} \beta_{i} N_{i}\left(t_{C}\right)+\mu_{j i} \beta_{j} N_{j}\left(t_{C}\right)}=\frac{\mu_{j i} \beta_{j}\left(N_{j}\left(t_{C}\right)-N_{j C}\left(t_{C}\right)\right)}{\mu_{i j} \beta_{i} N_{i}\left(t_{C}\right)+\mu_{j i} \beta_{j} N_{j}\left(t_{C}\right)} .
$$


The network effect factor $M\left(t_{c}\right)$ accurately reflects the scaling of the network effects. Indeed, if converters are one-way and/or imperfect, $\hat{u}_{i}\left(t_{c}\right)$ does not completely comply with the principle of network effects. For example, if converters are one-way with $\mu_{i j}=0$ and $\mu_{j i} \neq 0$, then $\hat{u}_{i}\left(t_{c}\right)=I$. That is, the normalized utility benefits no longer include the network effects due to converters and users get the maximum possible utility from conversion, independently from the respective network sizes. Therefore, the network effect factor can be defined by $M\left(t_{C}\right)=\frac{\mu_{A B} N_{A}\left(t_{C}\right)+\mu_{B A} N_{B}\left(t_{C}\right)}{N_{A}\left(t_{C}\right)+N_{B}\left(t_{C}\right)}$, representing the relative network sizes over the market size at the present time $t_{c}$ and thus captures the network size effects.

To determine the adoption probability of converters, we need to compare the utility from buying a converter $U_{i}\left(t_{c}\right)$ to the disutility associated with third-party converters. This disutility is composed of an objective part and a subjective part: The objective part is impacted by converter price $P_{c} \in[0,1]$ (normalized over a maximum price) and an objective quality measure $Q_{c} \in[0, I]$, including aspects such as reliability or degree of conversion complying with the converter function (transfer of compatibility benefits). We represent this objective part by a parameter $D$ such that $D \equiv D\left(P_{c} ; Q_{c}\right)$.

The subjective part depends on the consumer willingness to buy third-party converter $C$, as well as by the delay between the decisions at times $t_{c}$ and $t_{i}$. The consumer willingness to buy a converter is represented by a parameter $Y \in[0,1]$. If $Y=1$, a consumer has the highest willingness to buy a converter. If $Y<I$, the highest willingness is altered by a lack of acceptance. For example, if the converter is a software product, a consumer might perceive that it slows performance or contains unwanted add-ons, spyware or even viruses - even if objectively speaking neither would be true. In this analysis, we allow for a uniform distribution of the willingness to buy third-party conversion in terms of consumer perception, i.e., $Y \sim$ Uniform $(0, I)$.

The subjective part is furthermore impacted by the delay between the two decisions at times $t_{c}$ and $t_{i}$. The decision delay corresponds to a memory effect: A consumer entering the market at time $t_{i}<t_{c}$ has less infor- mation with respect to converter existence or less interest for new complementary products in the market than a consumer entering at time $t_{c}$. Therefore, the lower the information or interest level, the higher the loss of utility associated with conversion. We model this decision delay by a function $\psi\left(t_{c}, t_{i}\right)=e^{-\gamma\left(t_{C}-t_{i}\right)}$, with $\gamma$ $\in[0, \mathrm{I}]$.'

One way to define the disutility associated with thirdparty converters is thus: $\delta\left(Y, \psi\left(t_{c}, t_{i}\right)\right)=D\left(I-Y \psi\left(t_{c}, t_{i}\right)\right)$. This disutility function sensibly captures the objective effects of price and quality in relation with the subjective willingness and memory to buy converters. That is, for a user entering the market at time $t_{i}$, the lower the willingness $Y$ and the higher the disutility parameter $D$, the higher the disutility. In particular, $\delta\left(Y, \psi\left(t_{c}, t_{i}\right)\right)$ has been specified such that consumers with willingness to buy conversion $Y=I$ and $t_{c}=t_{i}$ do not incur disutility associated with conversion. Furthermore, even if the converter is free $\left(P_{c}=0\right)$ and its quality is perfect $\left(Q_{c}=1\right)$, consumers with a reduced willingness to adopt converters $Y<1$ and/or a decision delay $\left(t_{c}-t_{i}\right)>0$ should incur disutility. Indeed, if free and perfect conversion software existed, users still might not want to download and/or install it, which often happens in reality in the context of third-party converter provision.

Based on the above modeling choices, we can determine the conditional adoption probabilities of third-party converters given the use of a base technology. For an $i-$ user, this probability can be expressed as:

$$
\begin{aligned}
p_{(C \mid i)}\left(t_{C}, t_{i}\right) & =P\left(U_{i}\left(t_{C}\right)>D\left(1-Y \psi\left(t_{C}, t_{i}\right)\right)\right) \\
& =\quad P\left(Y>\frac{1}{\psi\left(t_{C}, t_{i}\right)}-\frac{\hat{U}_{i}\left(t_{C}\right)}{D \psi\left(t_{C}, t_{i}\right)}\right) \\
& =\quad 1-\int_{0}^{\frac{1}{\psi\left(t_{C}, t_{i}\right)}-\frac{\hat{U}_{i}\left(t_{C}\right)}{D \psi\left(t_{C}, t_{i}\right)}} d y \\
& =1-\frac{1}{\psi\left(t_{C}, t_{i}\right)}\left(1-\frac{U_{i}\left(t_{C}\right)}{D}\right) .
\end{aligned}
$$

\footnotetext{
I In marketing, there is a strong evidence of a correlation between forgetting and the passage of the time. For example, Little and Lodish (1969) have modeled the fading memory of consumers with an exponential time-dependent decay.
} 
Note, Equation 3 holds only if $\psi\left(t_{c}, t_{i}\right) \geq 1-\frac{U_{i}\left(t_{C}\right)}{D}$, while for $\psi\left(t_{c}, t_{i}\right)<1-\frac{U_{i}\left(t_{C}\right)}{D}, p_{(C \mid)}\left(t_{c}, t_{i}\right)=0$, as the memory $\psi\left(t_{c}, t_{i}\right)$ is so weak that no consumer adopts a converter at time $t_{c}$.

From this, we can consider the elements of the technology adoption with availability of converters (Figure I). In Subsection 3.2.1, we characterize how consumers who bought a base technology before $T$ respond to converter introduction. In Subsection 3.2.2, we determine how each new consumer joining the market between $T$ and $t_{\text {lock }}(T)$ decides on the adoption of a base technology and a converter. In Subsection 3.2.3, we describe consumer reaction to technology lock-in at time $t_{\text {lock }}(T)$.

\subsection{Converter introduction}

At time $T \geq 0$, third-party converters $C$ are introduced. We assume that all consumers who have previously bought a base technology now make a decision about buying or not buying a converter $C$ as a complement. The installed bases $N_{A}(T)$ and $N_{B}(T)$ are distributed between converter adopters and non-adopters, such that $N_{A C}(T)$ and $N_{B C}(T)$ represent the conditional installed bases of converter adopters at time $T$. These installed bases are jointly defined by

$N_{A C}(T)=\int_{0}^{T} p_{A}(t) p_{(C \mid A)}(T, t) d t$

and

$N_{B C}(T)=\int_{0}^{T} p_{B}(t) p_{(C \mid B)}(T, t) d t$, respectively, with

$p_{i}(t)$ being given by Equation 2. Therefore, the converter introduction sales can be expressed as $S_{I}(T)=\sum_{i=A, B} \int_{0}^{T} p_{i}(t) p_{(C \mid i)}(T, t) d t$.

\subsubsection{Adoption of base technologies with availability of converters}

In this phase of the technology adoption process ( $t \in$ $\left.\left[T, t_{\text {lock }}(T)\right)\right)$, consumers take the availability of third-party converters into account while choosing a base technology $A$ or $B$. To explicitly incorporate the availability of converters into the adoption process of base technologies $A$ and $B$, we adapt Equation I, using the utility functions $u_{A \bar{C}}(t)$ and $u_{B \bar{C}}(t)$ that comprise conversiongenerated benefits, such that $p_{i, \text { conv }}(t)=\frac{\theta_{A} \lambda_{A}+\theta_{B} \lambda_{B}}{\lambda_{A}+\lambda_{B}}+\frac{u_{i \bar{C}}(t)-u_{j \bar{C}}(t)}{\lambda_{A}+\lambda_{B}}$. We develop this expression, and determine the general condition for adoption of base technology $i$ in the presence of third-party converters as follows:

$$
\begin{aligned}
\frac{d}{d t} p_{i, \text { conv }}(t)= & \frac{1}{\lambda_{A}+\lambda_{B}}\left(-\beta_{j}+\mu_{j i} \beta_{j} p_{(C \mid j)}(t)\right) \\
& +\frac{1}{\lambda_{A}+\lambda_{B}}\left(\beta_{i}+\beta_{j}-\mu_{j i} \beta_{j} p_{(C \mid j)}(t)-\mu_{i j} \beta_{i} p_{(C \mid i)}(t)\right) p_{i, \text { conv }}(t) .
\end{aligned}
$$

As $P_{(C \mid)}(t)$ and $P_{(C \mid j)}(t)$ depend on the installed bases $N_{i}(t)$ and $N_{i c}(t) \quad-$ and thus on $p_{i, c o n v}(t)$ as $N_{i}(t)=N_{i}(T)+\int_{T}^{t} p_{i, \text { conv }}(\tau) d \tau \quad$ and $N_{i C}(t)=N_{i C}(T)+\int_{T}^{t} p_{i, \text { conv }}(\tau) p_{(C \mid i)}(\tau) d \tau-$ Equation 4 appears not to be analytically tractable. We can however use numerical methods to solve it and to conduct sensitivity analysis to determine implications of third-party converter introduction on the technology adoption process.
Hence, we can characterize the converter postintroduction sales. We assume that, between $T$ and $t_{\text {lock }}(T)$, each consumer joining the market simultaneously decides on the purchase of a base technology and a converter (i.e., $\left.t_{i}=t_{c}\right)$. This implies $\psi\left(t_{c}, t_{i}\right)=I$ for all $t_{\text {; }}$ $t_{c} \in\left[T, t_{\text {lock }}(T)\right)$. The post-introduction sales can be ex-

$$
\begin{aligned}
& \text { pressed as } S_{I I}(T)=\int_{T}^{t_{\text {lock }}(T)}\left(p_{A, \text { conv }}(t) p_{(C \mid A)}(t, t)\right. \\
& \left.+p_{B, \text { conv }}(t) p_{(C \mid B)}(t, t)\right) d t
\end{aligned}
$$




\subsubsection{Technology lock-in}

At time $t_{\text {lock }}(T)$, one of the base technologies wins the standards battle and locks in the market. The losing technology (technology I) gradually disappears for all $t \geq$ $t_{\text {lock }}(T)$ and thus no new complementary technologies are introduced into the losing network. The users of technology I not possessing a converter will be considered $S_{I I I}(T)=\int_{0}^{T} p_{l}(t)\left(1-p_{(C \mid l)}(T, t)\right) p_{(C \mid l)}\left(t_{\text {lock }}(T), t\right) d t+\int_{T}^{t_{\text {lock }}(T)} p_{l, \text { conv }}(t)\left(1-p_{C l}(t)\right) p_{(C \mid l)}\left(t_{\text {lock }}(T), t\right) d t$.

In this section, we developed a mathematical model for the adoption of third-party converters and their effect on the adoption of competing, incompatible technologies. We made a specific set of assumptions on objective and subjective consumer perception of third-party converters. Our model abstractions are a first attempt to capture the essential trade-offs and to provide insights on implications of third-party converter introduction on the adoption process of base technologies. In the next section, we describe how third parties can maximize their profit and how incumbents can anticipate and react to third-party converter introduction.

\section{Managerial Insights}

In this section, we consider the interdependence between incumbents' and third parties' businesses. We address our research questions to discuss implications of third-party converter introduction as based on our mathematical model. In Subsection 4.I, we investigate which converter introduction strategies are followed by third parties. In Subsection 4.2, we analyze the effects of third-party converter introduction on the incumbents' business. In Subsection 4.3, we present how the incumbents can anticipate and react to third-party converter introduction.

\section{I Conversion strategies of third-parties}

We determine which strategic options can be followed by companies willing to introduce converters. To do so, we assume that such third parties try to maximize their profit - if third parties have a commercial interest as well as if they have a "revolutionary" objective (such as disrupting dominant incumbents in their way to lock a market). Assuming constant converter price and negligimargin. post-introduction sales and the lock-in sales. benefits given to the winning network. ter sales maximization, respectively.

\section{I.I Introduction time and conversion option}

as "orphaned" (see Gandal et al., 1999). To avoid it, these users can either switch to the other network or buy a converter. We therefore assume that, at time $t_{\text {lock }}(T)$, these users reconsider whether they want to adopt or not adopt a converter $C$. The converter lockin sales in the third phase of the technology adoption process are expressed by

ble marginal cost over time ${ }^{2}$, third parties maximize their profit if they maximize converter sales. Indeed, the more units third parties can sell or distribute, the lower the fixed cost per unit and thus the higher the profit

Therefore, the sales maximization problem can be expressed as $\max _{T \geq 0} S(T)$, where $S(T)=S_{1}(T)+S_{I I}(T)+$ $S_{\text {III }}(T)$ is the sum of the converter introduction sales, the

To maximize their sales, third parties can decide on the introduction time $\mathrm{T}$ and conversion option. We assume that sales can be maximized with full conversion $\left(\mu_{A B} \rightarrow\right.$ I) being offered, as the maximum conversion-generated benefits can be captured. We therefore consider the following conversion options: (I) Full two-way conversion, (2) full one-way converters with conversiongenerated benefits given to the losing network, and (3) full one-way converters with conversion-generated

In Subsection 4.I.I, we analyze third parties' maximization decisions on optimal converter introduction time and conversion option. In Subsections 4.I.2 and 4.I.3, we present how the consumer memory effect as well as the price and quality levels influence third-party conver-

We explore how third parties can maximize their sales by deciding on converter introduction time, and on the

\footnotetext{
${ }^{2}$ As converters can be considered information goods, in Shapiro and Varian's (1999a) broad sense, the fixed cost of producing them may be high, while the marginal cost of reproducing them are low.
} 
three aforementioned conversion options. For our numerical illustrations, the following parameter values are assumed: $\alpha_{A}=50, \alpha_{B}=49, \lambda_{A}=15, \lambda_{B}=10, \theta_{A}=$ $0.25, \theta_{B}=0.75$, while the other parameters depend on the respective analysis. For example, technology $A$ could correspond to Apple's iPod and technology $B$ could be Microsoft's Zune, in the presence of a converter $C$ provided by a third party. For the rationale underlying the parameter values, we refer to Seifert and Varé (2009).

In this analysis, we fix the values $\beta_{A}=\beta_{B}=0.005, D=$ I.5, $\gamma T=0.5$ and $N_{A}(0)=0$. The robustness of the following numerical results to derive managerial implications has also been tested. By applying all feasible parameter combinations within the feasible ranges $\alpha_{i} \geq$ $0, \beta_{i}>0, \lambda_{i}>0, \theta_{i} \in[0, I]$ and $D \geq I$, such that $p_{i}(0) \in$ $(0, I)$, qualitatively the results remain the same. Fur- thermore, all values can be considered as normalized values since we use our model to describe various network markets. For example, while the installed bases are hereby presented with multiples of hundreds, they may correspond to multiples of millions in reality.

Varying the parameters $T$ and $N_{B}(0)$, we observe that

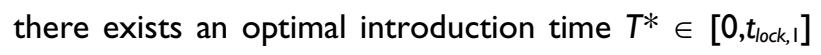
such that the total sales of third-party converters are maximized, i.e., $S\left(T^{*}\right)=\max _{T \geq 0} S(T)$. As an illustration, Figure 2 shows the evolution of two-way converter sales $S(T)$ along with the introduction time $T$ for four different initial installed bases $N_{B}(0)$. The maximum of each curve $S(T)$ (i.e., the point $S\left(T^{*}\right)$ ) occurs at a different time $T^{*}$ for each initial situation and is linked to the abscissa by a dashed line. The same observation also holds with one-way converters.

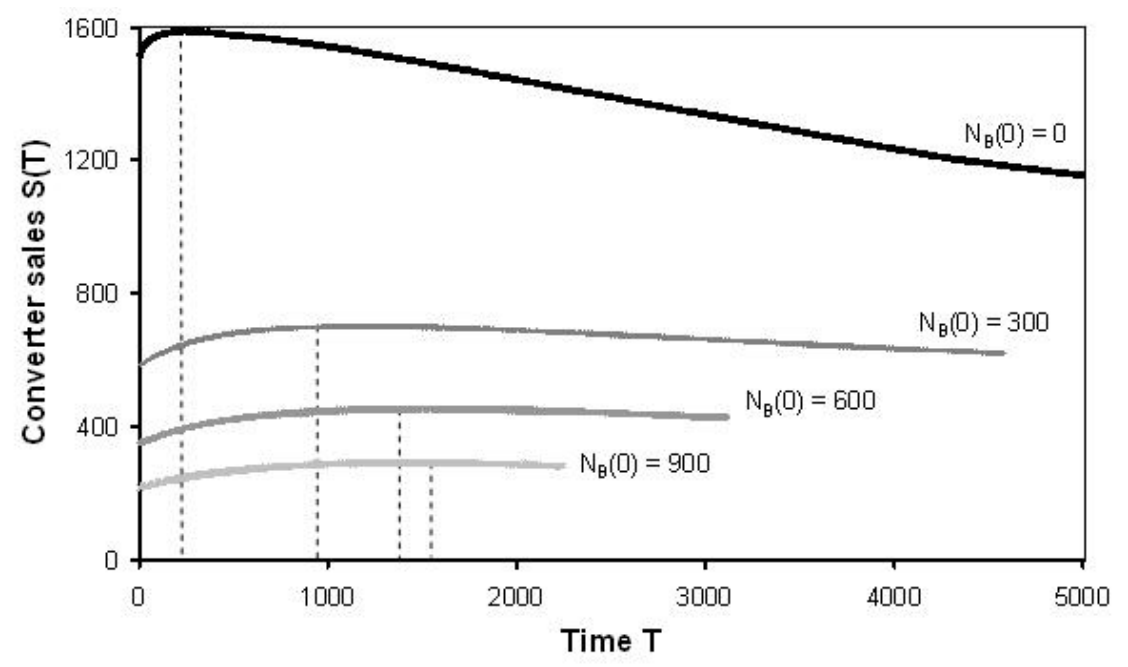

Figure 2. Converter sales $S(T)$ for different installed bases $N_{B}(0)\left(N_{A}(0)=0\right)$.

There is a relation between the optimal converter sales $S\left(T^{*}\right)$ and the size of the installed bases. For all three conversion options, the smaller the installed base $N_{B}(0)$, the higher the optimal converter sales $S\left(T^{*}\right)$ (with $N_{A}(0)$ $=0$ ), as explicitly depicted in Figure 3. Our model then predicts that third parties will favor situations with both technologies entering the market at the same time and needing to create their own installed bases (i.e., $N_{A}(0)$ $\rightarrow 0$ and $N_{B}(0) \rightarrow 0$ ) - say a symmetric standards war. In such situations, the maximum sales $S\left(T^{*}\right)$ are higher and introducing converters is more profitable for third parties than in asymmetric standards wars, where $N_{i}(0)$ $>N_{j}(0)$. 


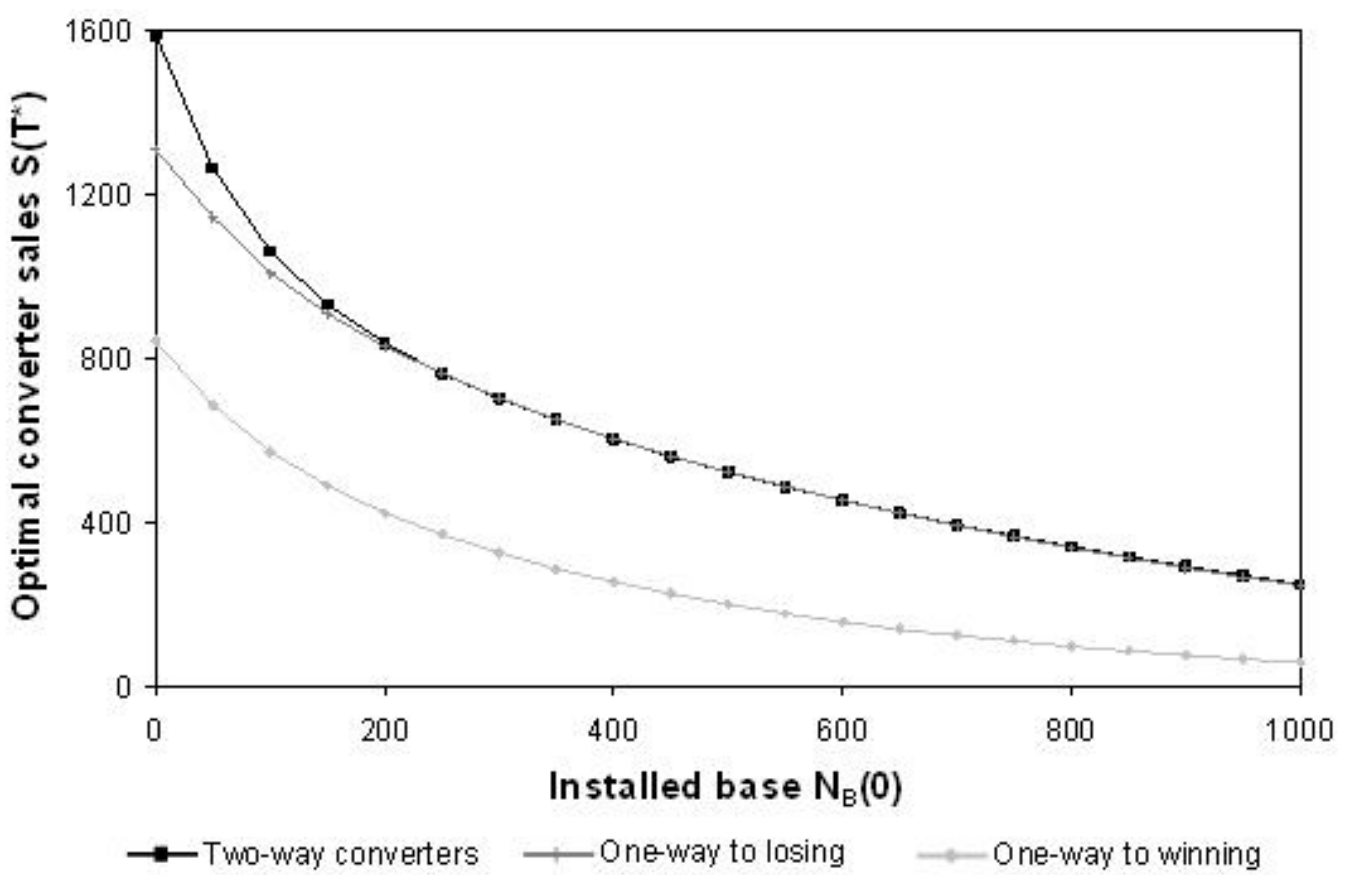

Figure 3. Optimal converter sales $S\left(T^{*}\right)$ as a function of $N_{B}(0)$.

Therefore, we can expect that third parties tend to survey the technological environment and the occurrence of recent standards wars and thus plan converter introduction well in advance. For example, before the format war for high definition DVDs between HD-DVD and Blu-ray broke out - before any players or contents (movies, console games, etc.) had ever been produced with either format - Samsung and LG Electronics had already planned to introduce a combo HD-DVD/Blu-ray player. In such a case, introducing converters early may appeal to users of both networks who do not apparently know which technology will win the war. ${ }^{3}$ On the other hand, there is no reason for third parties to prospect for asymmetric standards war. For example, there was no preannouncement of the converter introduction between Apple's iPod and Microsoft's Zune before the

\footnotetext{
${ }^{3}$ Samsung however had to draw back from this plan because of impossible licensing agreements (see Kanellos, 2006a). LG Electronics had indicated that such a combo player did not have a place in its product pipeline any more (Kanellos, 2006b), before announcing the introduction of a player supporting both formats (Ihlwan, 2007). At the same time, a new type of high-definition discs - Total HD Discs - has been created by Warner Bros, which can play films and television programs in both Blu-ray and HD-DVD technologies. One of Warner Bros's objectives was to comply with needs of confused consumers by allowing the competing formats to be put on separate disc layers (Siklos, 2007).
}

latter portable player had been introduced. The iPod was already considered the market leader with a significant majority of the market share. ${ }^{4}$

Besides the optimal converter sales, there is also a relation between the optimal introduction time and the installed base sizes for each conversion option. Figure 4 illustrates the absolute optimal introduction time $T^{*}$ in function of the installed base $N_{B}(0)$ (on the left side) and the relative optimal introduction time $\frac{T^{*}}{t_{\text {lock }}}=\inf \left\{t_{\text {lock }}(T), t_{\text {lock }, 1}\right\}$ (on the right side). For two-way converters and one-way converters to the winning network, the optimal introduction time $T^{*}$ increases if $N_{B}(0)$ increases. While $T^{*}$ is always early in the adoption process with one-way converters to the winning network, $T^{*}$ increases towards the end of the adoption process with two-way converters. For oneway converters to the losing network, the optimal introduction time $T^{*}$ decreases if $N_{B}(0)$ increases, and $T^{*}$ always corresponds to $t_{\text {lock. }}$.

\footnotetext{
${ }^{4}$ Zune can import and play files from user libraries in several formats including MP3, WMA and Apple's AAC, but only if these files are unprotected (Lombardi, 2006). In this regard, Zune vs. iPod still constitutes a standards war.
}

ISSN: 07I8-2724. (http://www.jotmi.org)

Journal of Technology Management \& Innovation (C) Universidad Alberto Hurtado, Facultad de Economía y Negocios 

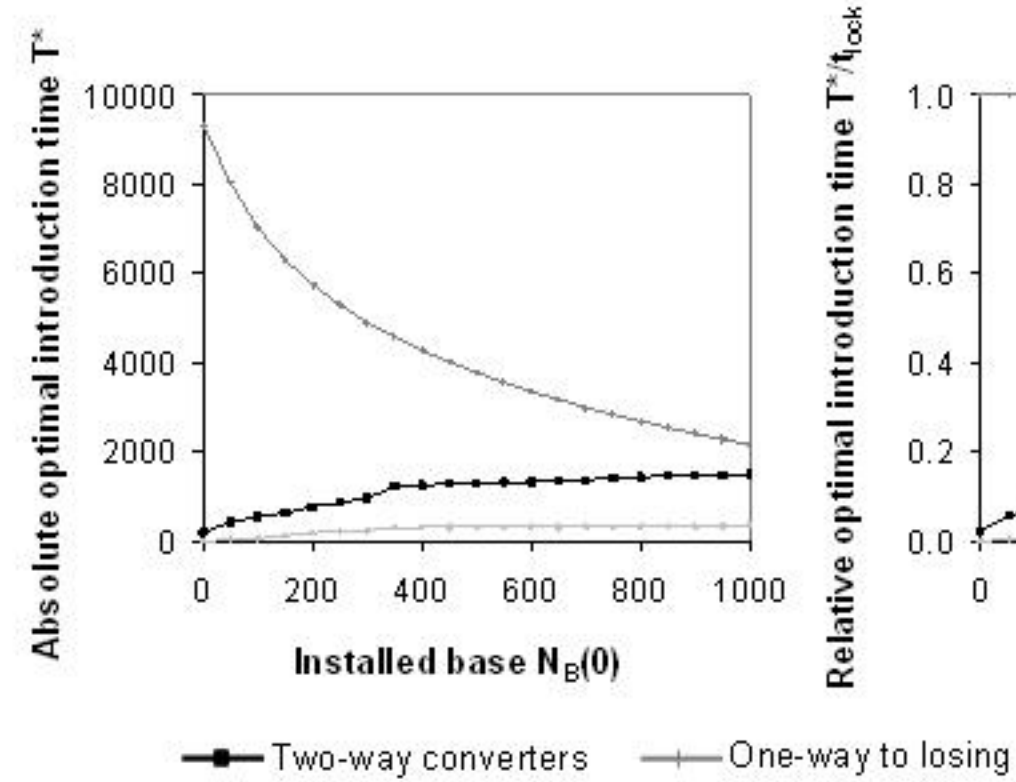

_- One-way to winning

Figure 4. Absolute (left) and relative (right) optimal introduction time $T^{*}$ as a function of $N_{B}(0)$.

Therefore, we can compare the profitability of the different conversion options. The converter sales $S(T)$ with one-way converters designed for the winning network are smaller than with other converters. Users in a winning network have indeed less benefits to buy a converter, as their technology will eventually lock in the market. For example, there is no sensible reason to give conversion-generated benefits only to Skype users to connect to competing VolP networks, because Skype dominates the VolP market. Thus, this conversion option will not be considered further.

Either two-way converters or one-way converters to the losing network may coexist as strategic options. If the standards war is asymmetric, the maximum converter sales are equal for both conversion options (Figure 3). If the standards war is symmetric, the maximum sales with two-way converters are always greater, while the optimal introduction time is earlier than with one-way converters (Figure 4). Therefore, third parties will tend to introduce two-way converters. In case third parties are not able to introduce two-way converters at the optimal time, they can decide to introduce one-way converters later to minimize the loss due to delayed converter introduction.
However, introducing one-way converters is risky for third parties. As third parties need to plan converter introduction well in advance, they thus need to know which technology network might lose the standards battle. Without this information, third parties might give full one-way conversion benefits to the users of the winning technology, which would imply converter suboptimal adoption. Although the initial conditions of the competition determine the path of the technology adoption process and thus the winning technology in the absence of converters (see Equation 2), early indicators might change. For example, in the next generation DVD market, the bias for either competing format has changed due to changes in strategic considerations of different market players. While Blu-ray was first seen as the potential winner, some players of the multimedia industry joined the HD-DVD consortium giving it a greater initial advantage over Blu-ray.

Hence, major drivers for these two strategies are the risk aversion and time-to-market constraint. For instance, if the time-to-market is significant (e.g., due to required converter development) third-party providers would be better off to aim for two-way conversion. These strategic options also depend on consumer memory effect, and on converter price and quality. 


\subsubsection{Memory effect}

There is a memory effect for consumers if there is a delay between the purchase of a base technology and a converter (modeled by parameter $\gamma$ in Subsection 3.2). In our model, this holds for users buying converters at times $T$ and $t_{\text {lock }}(T)$, realizing the converter introduction sales and the lock-in sales, respectively. Factors influencing consumer memory may be, for example, loss of awareness for market development or reduction of base technology use. That is, the longer the delay, the weaker the memory about converter existence (the lower the awareness for converter availability). Therefore, the parameter $\gamma$ is a function of converter purchase time such that $\gamma \equiv \gamma\left(\frac{1}{t_{R}}\right)=K \frac{1}{t_{R}}$, with $t_{R} \in\left\{T, t_{\text {lock }}(T)\right\}$ and $K \in[0, I]$ being a constant. The memory effect thus depends on the fraction $K=\gamma T=t_{\text {lock }}(T)$.

The consumer memory effect influences third-party converter sales maximization. Fixing the values of $\beta_{A}=$ $\beta_{B}=0.005, N_{A}(0)=0, N_{B}(0)=300$ and $D=1.5$, the influence of $\gamma T$ (or $\gamma t_{\text {lock }}(T)$ ) on the optimal converter sales $S\left(T^{*}\right)$ and on the optimal converter introduction time $T^{*}$ is shown in Figure 5.
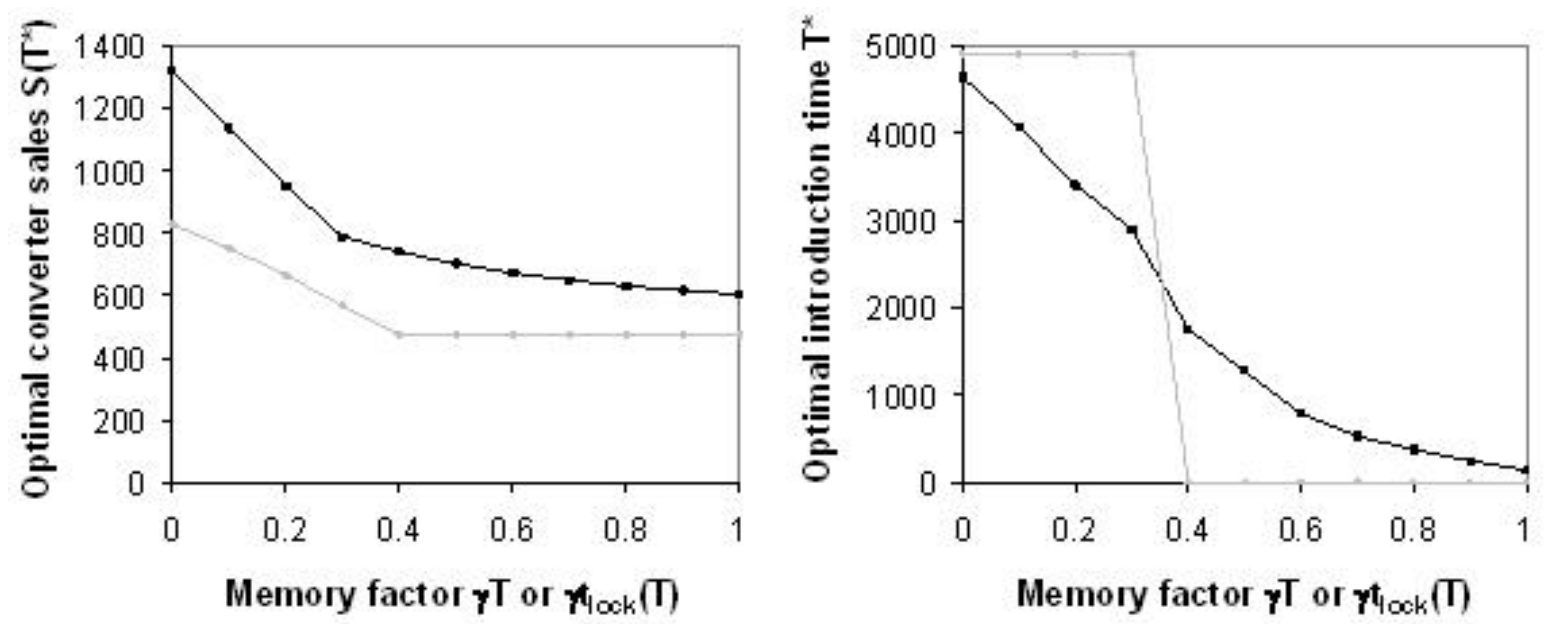

Figure 5. Influence of memory factor on optimal sales (left) and introduction time (right).

We can distinguish two different zones for low and for high values of $\gamma T$ (on each side of $\gamma T=0.3$ in Figure 5). For low values of $\gamma T$ (high awareness), the optimal converter sales are higher and the optimal introduction time is later. For high values of $\gamma T$ (low awareness), the optimal converter sales are smaller and the optimal introduction time is earlier in the adoption process. Therefore, third parties can delay converter introduction towards the end of the technology adoption process and capture more sales when consumer awareness for the conversion issue is relatively high. For example, in the classic standards battle in the microcomputer industry, conversion software had emerged only at the end of the technology adoption process (when IBM- compatible computers were considered to have won the race over Macintoshes). The awareness was high as almost every consumer knew the problems related to computer interoperability.

One way to influence consumer memory effect is related to the marketing efforts of third parties. Indeed, there is a trade-off for third parties given the relation between maximum converter sales and marketing efforts: The maximum sales may be higher with a one-way converter and high awareness than with a two-way converter and low awareness. Therefore, a change of marketing efforts can change the optimal conversion option. 


\section{I.3 Effect of converter price and quality}

Converter price and quality are included in the disutility parameter $D$ (see Subsection 3.2). Therefore, they also influence converter sales maximization. Independently from the time of introduction, the higher $D$ the lower the sales.
There is another trade-off between $D$ and the memory effect, since they are related in the definition of the disutility. Indeed, weak consumer memory can be compensated by high converter quality and low converter price. Figure 6 presents the influence of the memory $\gamma T$ or $\gamma t_{\text {lock }}(T)$ on the optimal converter sales $S\left(T^{*}\right)$ for several values of $D$.

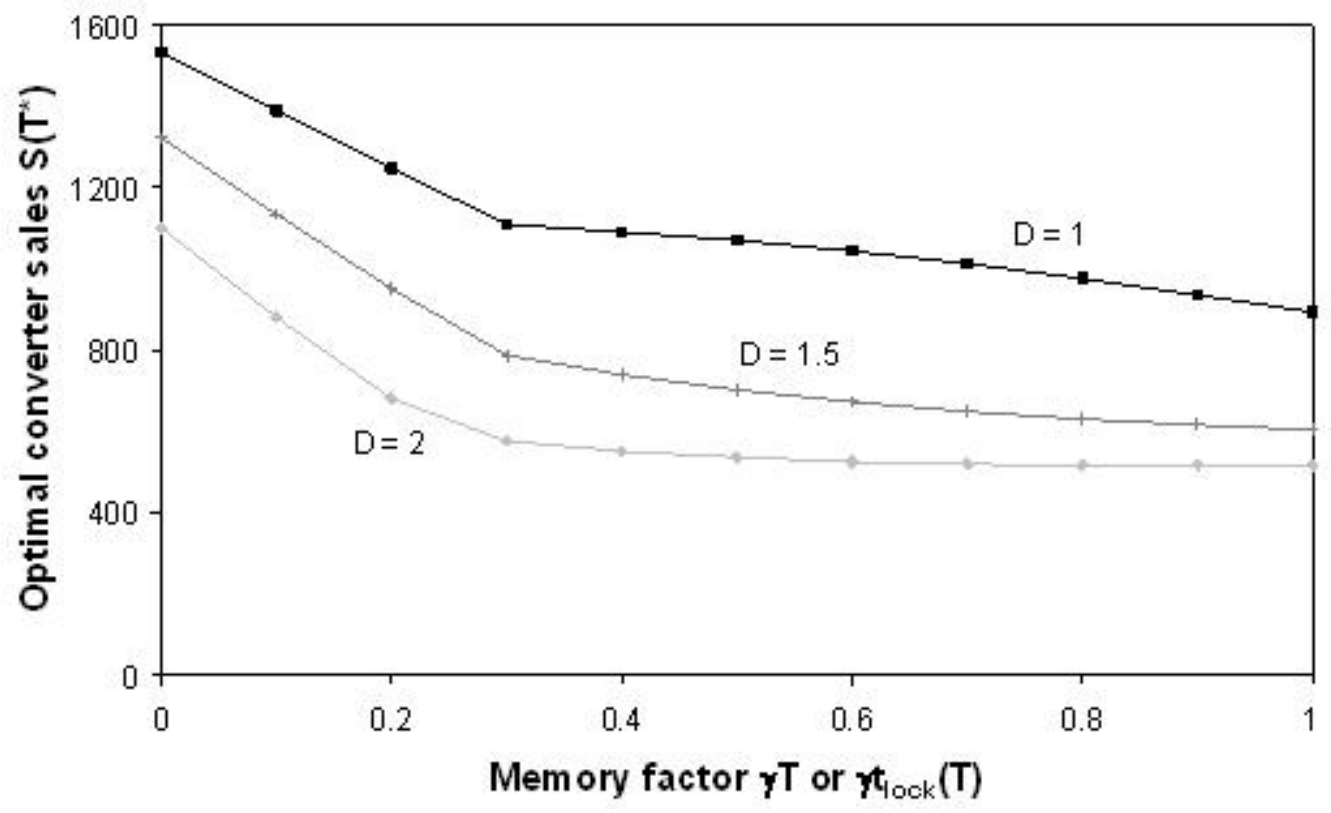

Figure 6. Influence of converter price and quality (D) on optimal converter sales.

For all values $\gamma T$, the maximum converter sales are greater for low $D$ (converters with high quality and low price) than for high $D$. Therefore, the same level of sales can be reached with low awareness $\gamma T$ and low disutility parameter $D$ as with high awareness and high disutility.

\subsection{Effects of third-party converters on adoption process of base technologies}

Having identified how third parties can maximize their sales, we analyze how third-party converter introduction directly impacts the adoption process of competing base technologies. Converter introduction interferes with the standards war by modifying the lock-in process of the base technologies. When converters are not available, one competing technology locks in the market

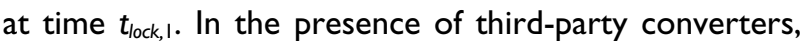
competing technologies lock in at time $t_{\text {lock }}(T)$, which may be different from $t_{\text {lock, }}$ as being dependent on the introduction time $T$.

For all values of introduction time $T \in\left[0, t_{\text {lock, }, 1}\right)$, we find that a dominant effect on the lock-in process of incompatible, competing base technologies in the presence of third-party converters is process acceleration. Acceleration of the lock-in process occurs if one competing technology locks in the market in the presence of converters earlier than when converters are not available, i.e., if $t_{\text {lock }}(T)<t_{\text {lock, }}$. Figure 7 shows the relative acceleration of the lock-in process, $\frac{t_{\text {lock,1 }}-t_{\text {lock }}(T)}{t_{\text {lock }, 1}}$, as a function of $T$ for different initial situations with one-way converters for losing technology users (on the left side) and two-way converters (on the right side). The different functions represent a measure of the intensity of 
acceleration. For one-way as well as for two-way converters, the earlier the converter introduction, the

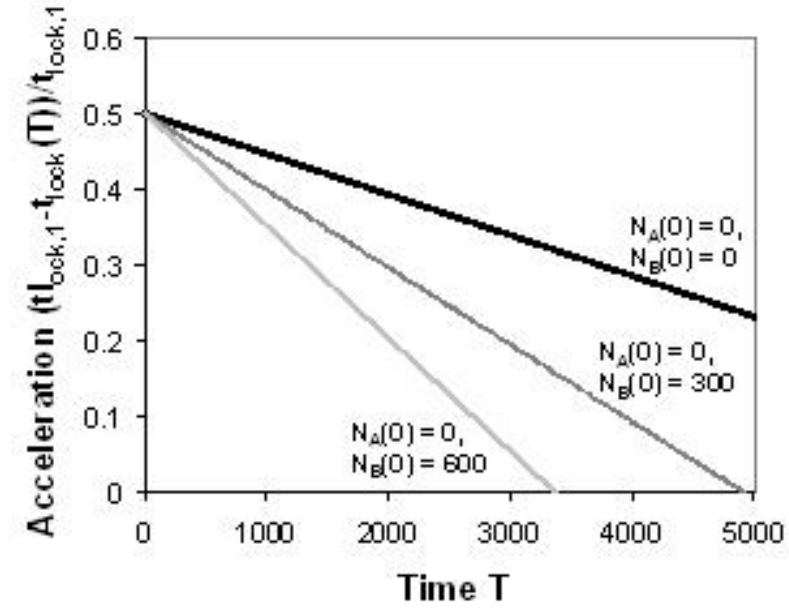

greater the intensity of acceleration on the lock-in process of competing technologies.

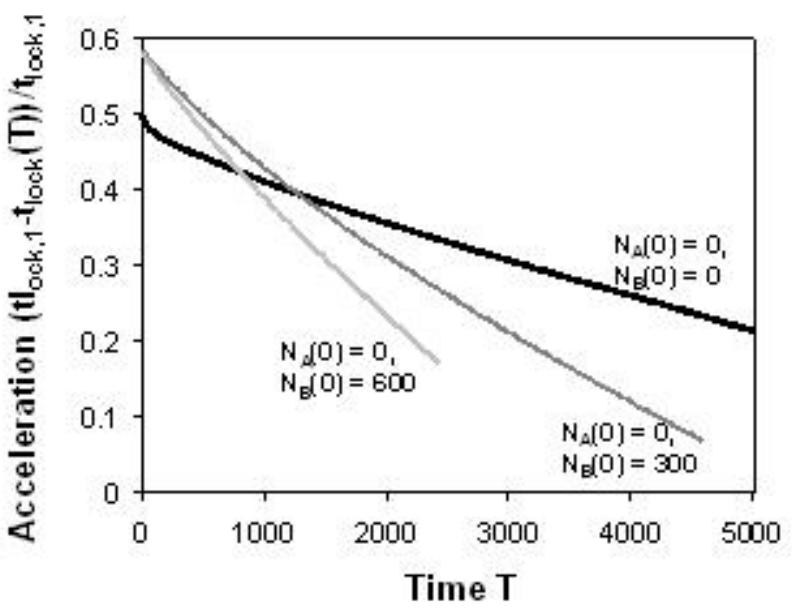

Figure 7. Relative acceleration of lock-in process with one-way (left) and two-way converters (right).

There may be rare exceptions to acceleration where the lock-in process gets extended. This holds only for impractical parameter values with one product characteristic close to 0 . Yet, in our model setting, there is a fundamental variation between third-party and incumbent-provided converters: While incumbent-provided converters may accelerate, extend or reverse the lockin process in every configuration depending on the introduction time (see Seifert and Varé, 2009), third-party converters most prominently accelerate it. One reason is that third parties do not manipulate the degrees of conversion by allowing for conversion options with partial compatibility, as they are independent from incumbents' business and always seek to maximize total converter sales. Even if third parties tried to extend the lock-in process by allowing for partial compatibility, full conversion would always capture more sales.

The intensity of acceleration on the lock-in process directly impacts incumbents' business by changing the market share level reached at the lock-in time. Figure 8 shows how the market share at time $t_{\text {lock }}(T)$ may change along with the introduction time $T$ (in a symmetric standards war as an example). The higher the intensity, the lower the market shares for dominant incumbents (the higher the market share for weak incumbents). The analysis is similar for one-way as well as for two-way converters. 


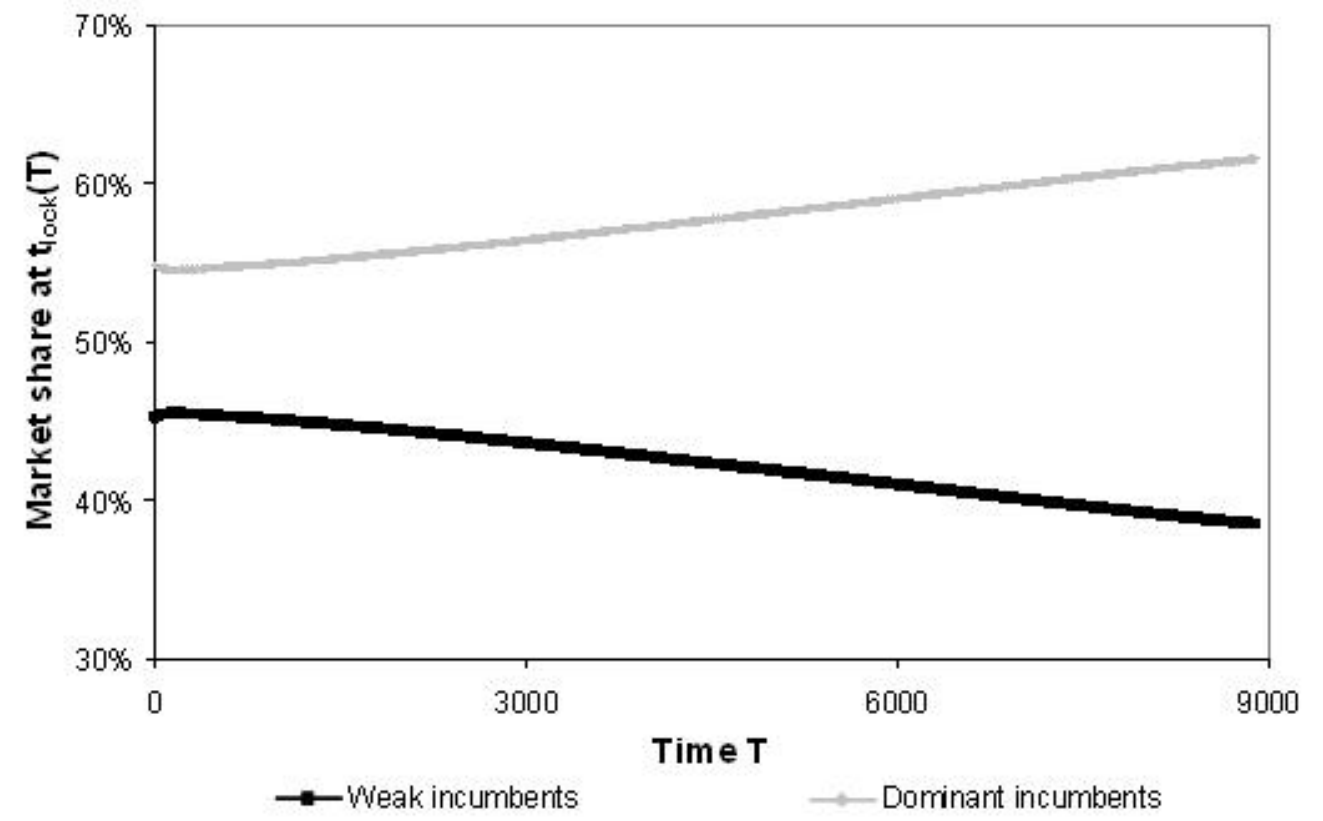

Figure 8. Effects of third-party converter introduction on market share.

The intensity of acceleration and the implications for market share would be experienced differently depending on the memory effect. If consumer awareness is high, third-party converters are optimally introduced at the end of the adoption process and thus the intensity of acceleration is low. If awareness is low, converters are introduced early in the adoption process, when the intensity of acceleration is strong. Table I provides a summary of the impact of acceleration on the adoption process of base technologies and distinguishes whether consumer awareness is low or high, and whether incumbents are dominant or weak (up and down arrows meaning positive and negative, respectively).

\begin{tabular}{lll}
\hline & Low aw areness & High aw areness \\
\hline$T^{*}$ & $\begin{array}{l}\text { Early to medium } \\
\text { optimal introduction }\end{array}$ & $\begin{array}{l}\text { Late optimal } \\
\text { introduction }\end{array}$ \\
\hline $\begin{array}{l}\text { Intensity of } \\
\text { acceleration at } T^{*}\end{array}$ & $\begin{array}{l}\text { From very high to high } \\
\text { intensity }\end{array}$ & Low(null) intensity \\
\hline & $\begin{array}{l}\text { Earlier lock-in } \\
\begin{array}{l}\downarrow \text { Impact on dominant time for further } \\
\text { planning } \\
\downarrow \text { Lower market share }\end{array}\end{array}$ & None \\
\hline $\begin{array}{l}\text { Impact on weak } \\
\text { incumbents }\end{array}$ & $\begin{array}{l}\downarrow \text { Earlier lock-in, less sales, less } \\
\text { time for further planning } \\
\uparrow \text { Higher market share }\end{array}$ & $\begin{array}{l}\downarrow \text { No help in fighting out } \\
\text { the standards war }\end{array}$ \\
\hline
\end{tabular}

Table I. Impact of acceleration on incumbents related to third parties' strategies. 
For dominant incumbents, converter introduction with high awareness has a low impact, as they are introduced at the end of the process. With low awareness, the dominant technology locks in the market earlier. This strengthens the dominant position in the market. However, the premature lock-in gives less time to plan and pursue further projects like upgrading actual products or developing new products, in order to keep this position. It also shortens the product life cycle and time to market in new product developments. Likewise, less market share at the lock-in time gives them less possibility to introduce new products. For example, in the video game market, none of the dominant firms in each console generation could prevent innovations from competitors and stay the market leader. Gallagher and Park (2002) show the circumstances under which Nintendo, Sega and Sony have respectively succeeded to each other as the dominant player in this market between the third and fifth generations. Furthermore, after having set the de facto standard thanks to converters earlier, dominant incumbents have to face the entry of small firms competing as early imitators. This is referred to as the "pesky little brothers" by Besen and Farrell (1994), the dominant incumbents being the "big brothers." These small firms would enter later in the absence of converters.

For weak incumbents, converter introduction paired with strong memory does not provide much help to fight out the standards war, even though losing technology users receive conversion-generated benefits. Converter introduction with weak memory may increase the utility for future users, but the market is nevertheless locked in earlier. This implies less sales and less time to strategically re-position by planning further projects or by gaining an installed base in a defined niche market, although the higher level of market share rises the potential to keep current users in the market niche. For example, the market share of Macintoshes has constantly decreased since the lock-in of the microcomputer market by IBM-compatible PCs (Reimer, 2005), demonstrating the difficulty of weak incumbents despite the availability of conversion. Likewise, de Vries and Hendrikse (200I) show that the weak incumbent in the Dutch banking chipcard industry had to withdraw its chipcard system from the market even after a two-way converter introduction. The weak incumbent had no other solution than coming back with a compatible solution with the dominant incumbent, at the cost of money and time.

Therefore, although third-party converters may comply with some consumer needs (above all with losing technology users), they have negative effects on weak incumbents as well as on dominant incumbents.

\subsection{Incumbents' reaction and anticipation strate- gies}

In network markets, incumbents try to set their products as de facto standards. As third-party converter introductions cannot be avoided by incumbents and have effects on the adoption process of base technologies, they represent a constraint for incumbents to reach their objective. This is particularly true, as third parties seek to maximize total converter sales.

In this subsection, we discuss anticipation and reaction strategies of incumbents to reduce this constraint. We distinguish between general strategies in de facto standardization processes (Subsection 4.3.I) and specific reaction strategies to third-party converter introduction. (Subsection 4.3.2). We show that incumbents are able to reduce third parties' incentive to introduce converters by taking actions, which should be integral to the overall strategies to establish a technology as the de facto standard.

\subsection{Strategies in de facto standardization processes}

Ehrhardt (2004) has developed a framework for analyzing strategies of companies in de facto standardization processes. In order to anticipate third-party converter provision, incumbents can take advantage of this framework to successfully establish their base technologies, by using tactics within positioning strategies and strategies for building an installed base. These tactics reduce the potential of third parties to become successful and thus obstruct possible converter introduction.

Accessibility strategy: Following Ehrhardt (2004), positioning strategies are based on two criteria: The leadership decision and the access decision. Leadership refers to incumbents' development of an own standard or adoption of an existing standard. Access regards incumbents' choice of whether to set their technology 
as proprietary or as open standard. The anticipation of a converter introduction directly relates to the access decision.

If incumbents decide to design a proprietary standard, they will make their system less accessible to their competitors as well as to third parties providing converters. They may either completely restrict access to third parties or agree on high-level licensing fees, which create entry barriers for third parties. If incumbents decide to set their technology as an open standard, access is, by definition, allowed to third parties (they may sometimes charge low licensing fees).

In addition to the entry barriers due to inaccessibility or high fees, third parties need to access two different networks to develop a converter. If at least one network is proprietary, third parties' incentive to produce converters is reduced. With two open networks, the incentive would already be reduced, as any entity should be able to produce converters.

Inaccessibility to networks might decrease converter quality - and especially the degrees of conversion - and increase converter price. Furthermore, in the first case of inaccessibility, the time to develop converters might be longer for third parties. They might thus not be able to introduce their converters at the optimal introduction time.

Therefore, incumbents should keep their networks as closed as possible to third parties, to reduce third parties' interest in developing converters. For example, in the standards wars in the high-definition DVD market, both incumbents (HD DVD and Blu-ray) have kept their network completely closed. This action allowed them to hinder LG to introduce a combo player at the beginning of the standards war, which would have implied profit maximization. Likewise, Samsung withdrew a similar project later due to loss of incentive to introduce it.

Such a measure may affect third parties' strategies. If the optimal introduction time is at the beginning of the adoption process, third parties may, for example, increase their marketing efforts to delay the introduction time, and to reduce the effect of closed networks.

Installed base creation: Strategies for building an installed base are relevant in de facto standardization processes as the early market phase determines which technology will win the standards war. Moreover, third parties favor symmetric standards wars to introduce converters. Therefore, if incumbents put efforts into creating an installed base, not only do they give themselves competitive advantages in the standards war, but they also build entry barriers for third parties.

Such efforts can be done by following strategies which will increase the network effects, like ensuring the provision of complementary products, penetration pricing or preannouncing market introduction of new products (Besen and Farrell, 1994; Ehrhardt, 2004). These efforts should increase the asymmetry between the installed bases. This implies a reduced potential to sell third-party converters.

Moreover, it is not only important for an incumbent to build an installed base faster than its competitors, but all incumbents also have to build their respective installed bases before third parties introduce converters.

\subsubsection{Reaction strategies to third-party converter introduction}

In addition to general strategies to establish a product as the de facto standard, some strategic options can be considered by incumbents to directly react to thirdparty converter introductions. Incumbents may develop their own converter or may influence consumer perception of degrees of conversion.

Incumbent-provided converters: By developing their own built-in converter, incumbents will control converter adoption by customers, as each customer buying the respective base technology will buy a converter at the same time. This reduces the potential sales of third-party converters as consumers buying a base technology including a built-in converter do not need to possess two converters.

Therefore, this strategic option can reduce the incentive of third parties to sell converters. Third parties may need to revise their strategy, by taking new measures so that the optimal introduction time falls at a later point in time to avoid the incumbents' reaction.

However, there may also be a game between the incumbents about which one has to produce converters. 
The result from this game could be that none of the incumbents are ready, from a strategic perspective, to introduce built-in converters.

Influence on consumer perception: As well as using tactics to influence consumer perception to adopt a base technology in de facto standardization processes (see a review of these tactics by Varé and Seifert, 2008), incumbents may influence consumer acceptance for third-party converters. By discrediting converters, incumbents can try to influence consumers' adoption willingness so that the perceived degrees of conversion are lower than the effective technical degrees of conversion. This decreases consumer utility for third-party converters.

Incumbents may also influence consumer memory with marketing measures. They may confuse consumers about converter functionality. For example, consumer confusion was a cause of Philips' failure to set the DCC (Digital Compact Cassette) technology as a standard (Hill, 1997).

With this strategic option, incumbents discourage third parties to provide converters in their market, as the action decreases the potential converter sales. As a consequence, third parties' strategic plans need to be changed or re-adjusted. As this option affects converter sales over time, third parties might need to re-schedule converter introduction to an earlier point in time. In the example of the standards war for the new generation of DVDs, the incumbents could not avoid the introduction of LG's combo player, but forced LG to adapt its strategy. For example, LG needed to increase its marketing efforts to avoid consumers' misperceptions, and to make clear that its player brings clear benefits. Likewise, by acting against LG, the incumbents avoid the entry of other third parties into the converter market.

\section{Conclusion}

In network markets, the provision of third-party converters is an important specification of standards wars for incumbents. In this paper, we analyzed the effects of third-party converter introduction on the adoption process of incumbents' base technologies. We developed a mathematical model for the conditional adoption of third-party converters in an adoption process of incompatible base technologies. We determined and discussed converter introduction strategies of third parties by establishing under what circumstances they maximize their profit, what the effects of third-party converters are on the adoption process of base technologies, and how incumbents can anticipate and react to third-party converter introduction.

We found that there is always an optimal time for thirdparty converter introduction such that converter sales are maximized. This time depends on the conversion option and consumer memory effect related to converter availability. Third parties prefer symmetric standards wars (both base technologies are introduced at the same time) from the outset because they have a greater potential of sales. They also favor full two-way converters as a conversion option to avoid the risk of developing one-way converters to the winning technology which implies converter suboptimal adoption.

Third-party converter introduction most prominently results in an acceleration of the lock-in process of the base dominant technologies. As a consequence of this acceleration, converters have negative effects on weak incumbents (loss of time to re-position) as well as on dominant incumbents (loss of time to upgrade or develop new products).

To reduce the constraint due to third-party converter introduction, incumbents have a series of strategic options at their disposal. By keeping their network closed, creating an installed base early, developing their own built-in converter and/or influencing consumer perception of converters, incumbents reduce the sales potential of third-party converters and they reduce third parties' interests in developing and introducing converters. For example, Apple Computer has been able to protect the iPod network from legal conversion providers so far.

Promising areas for further research remain: There is a need for empirical research on recent standards wars like in the markets of high-definition DVDs, the new generation of video game consoles, or portable multimedia players. This research could show evidence about the interdependence between third parties and incumbents in the long run. The coexistence of incumbentprovided and third-party converters in the market might be studied, highlighting the effects on incumbents' and third parties' businesses. Another interesting area in 
terms of market creation is the sequence of introducing new products after converter introduction because of the effects of converters on the lock-in process. Finally, while we have studied the impact of third-party converters from the incumbents' point of view, a study of social welfare could help policy makers in their analyses and decisions concerning markets regulation while in presence of market-driven standards setting processes.

\section{References}

ANDREOZZI, L. (2004) A Note on Critical Masses, Network Externalities and Converters. International Journal of Industrial Organization, 22(5), 647-653.

BESEN, S.M. and Farrell, J. (1994) Choosing How to Compete: Strategies and Tactics in Standardization. Journal of Economic Perspectives, 8(2), II7-134.

BLIND, K. (2004) The Economics of Standards: Theory, Evidence, Policy. Cheltenham, UK: Edward Elgar Publishing.

BRAUNSTEIN, Y.M. and White, L.J. (1985) Setting Technical Compatibility Standards: An Economic Analysis. Antitrust Bulletin, 30(2), 337-356.

CHOI, J.P. (1996) Do Converters Facilitate the Transition to a New Incompatible Technology? A Dynamic Analysis of Converters. International Journal of Industrial Organization, 14(6), 825-835.

CHOI, J.P. (1997) The Provision of (Two-Way) Converters in the Transition Process to a New Incompatible Technology. Journal of Industrial Economics, 45(2), I39153.

CHOU, C.f. and Shy, O. (1990) Network Effects Without Network Externalities. International Journal of Industrial Organization, 8(2), 259-270.

CHURCH, J. and Gandal, N. (1993) Complementary Network Externalities and Technological Adoption. International Journal of Industrial Organization, I I (2), 239260.

CHURCH, J. and Gandal, N. (1996) Strategic Entry Deterrence: Complementary Products as Installed Base. European Journal of Political Economy, I2(2), 33 I-354.
DAVID, P.A. (1987) Some New Standards for the Economics of Standardization in the Information Age. In P. Dasgupta and P.L. Stoneman (Eds.) Economic Policy and Technological Performance, Cambridge, UK: Cambridge University Press.

DAVID, P.A. and Bunn, J.A. (I988) The Economics of Gateway Technologies and Network Evolution: Lessons from Electricity Supply History. Information Economics and Policy, 3(2), I65-202.

DAVID, P.A. and Greenstein, S. (1990) The Economics of Compatibility Standards: An Introduction to Recent Research. Economics of Innovation and New Technology, I(I), 3-4I.

DE VRIES, H.J. and Hendrikse, G.W.J. (200I) The Dutch Banking Chipcard Game: Understanding a Battle Between Two Standards. International Studies of Management and Organization, 3I(I), 106-125.

ECONOMIDES, N. (1988) Variable Compatibility Without Network Externalities. Stanford University, Stanford, CA.

ECONOMIDES, N. and Viard, V.B. (2007) Pricing of Complements and Network Effects. NET Institute.

EHRHARDT, M. (2004) Network Effects, Standardisation and Competitive Strategy: How Companies Influence the Emergence of Dominant Designs. International Journal of Technology Management, 27(2/3), 272-294.

FARRELL, J. and Saloner, G. (1986) Installed Base and Compatibility: Innovation, Product Preannouncements, and Predation. American Economic Review, 76(5), 940955.

FARRELL, J. and Saloner, G. (1987) Competition, Compatibility and Standards: The Economics of Horses, Penguins and Lemmings. In H.L. Gabel (Ed.) Product Standardization and Competitive Strategy, Amsterdam; New York; Oxford; Tokyo: North-Holland.

FARRELL, J. and Saloner, G. (1992) Converters, Compatibility, and the Control of Interfaces. Journal of Industrial Economics, 40(I), 9-35. 
GABEL, H.L. (1987) Product Standards and Competitive Strategy: An Analysis of the Principles. INSEAD, Fontainebleau, France.

GALLAGHER, S. and Park, S.H. (2002) Innovation and Competition in Standard-Based Industries: A Historical Analysis of the U.S. Home Video Game Market. IEEE Transactions on Engineering Management, 49(I), 67-82.

GANDAL, N., Greenstein, S. and Salant, D. (1999) Adoptions and Orphans in the Early Microcomputer Market. Journal of Industrial Economics, 47(I), 87-103.

HILL, C.W.L. (1997) Establishing a Standard: Competitive Strategy and Technological Standard in WinnerTake-All Industries. Academy of Management Executive, II (2), 7-25.

HOTELLING, H. (1929) Stability in Competition. Economic Journal, 39(I53), 4I-57.

IHLWAN, M. (2007) LG: Bridging the Digital Disc Divide. BusinessWeek, January 5.

KANELLOS, M. (2006a) A DVD Combo? Don't Hold Your Breath. CNET News, April II.

KANELLOS, M. (2006b) Blu-ray/HD DVD Combo Still on Ice. CNET News, September 21.

KATZ, M.L. and Shapiro, C. (1994) Systems Competition and Network Effects. Journal of Economic Perspectives, 8(2), 93-II5.

LANCASTER, K. (1979) Variety, Equity, and Efficiency. New York, NY: Columbia University Press.

LEVINE, R. (2006) Unlocking the iPod. Fortune, October 23.

LITTLE, J.D. and Lodish, L.M. (1969) A Media Planning Calculus. Operations Research, 17(January-February), I35.

LOMBARDI, C. (2006) Zune Details Unzipped. CNET News, September 29.

MACKIE-MASON, J.K. and Netz, J.S. (2006) Manipulating Interface Standards As An Anti-Competitive Strate- gy. In S. Greenstein and V. Stango (Eds.) Standards and Public Policy, Cambridge, UK: Cambridge University Press.

MANENTI, F.M. and Somma, E. (2008) One-Way Compatibility, Two-Way Compatibility and Entry in Network Industries. International Journal of the Economics of Business, I5(3), 30I-322.

REIMER, J. (2005) Total Share: 30 Years of Personal Computer Market Share Figures. Ars Technica, December 14., http://arstechnica.com/articles/culture/ totalshare.ars.

RYST, S. (2006) Linux Linkup for Microsoft, Novell. BusinessWeek, November 3.

SEIFERT, R.W. and Varé, A.X. (2009) Adoption of Network Technologies in the Presence of Converters. Economics of Innovation and New Technology, I8(I), 69-91.

SHAPIRO, C. and Varian, H.R. (1999a) Information Rules: A Strategic Guide to the Network Economy. Boston, MA: Harvard Business School Press.

SHAPIRO, C. and Varian, H.R. (1999b) The Art of Standards Wars. California Management Review, 4I (2), 8-32.

SIKLOS, R. (2007) New Disc May Sway DVD Wars. CNET News, January 4.

SWANN, G.M.P. (2000) The Economics of Standardization. University of Manchester, Manchester, UK.

VARÉ, A.X. and Seifert, R.W. (2008) Contextual And Tactical Changes in Standards Wars: What Consequences For "Winners"? International Journal of Innovation and Technology Management, 5(4), 447-474.

VIARD, V.B. and Fan, S. (2005) The Long Battle for an Instant Messaging Standard, Case study, Stanford University, Stanford, CA. 